\title{
Exploring Mobile Technologies for the Urban Homeless
}

\author{
Christopher A. Le Dantec \\ GVU Center and School of Interactive Computing \\ College of Computing \\ Georgia Institute of Technology \\ Atlanta, GA. U.S.A. \\ ledantec@cc.gatech.edu
}

\begin{abstract}
My research examines the practical and social impact of technology on the urban homeless. To accomplish this, I have conducted interviews with the homeless to understand how technology - from mobile phones to bus passes - affects their lives. I have also conducted ethnographic fieldwork at care providers to understand how technology figures into the provision of care for the homeless. These formative studies have motivated the design of a set of information sharing services that aggregate information available in the community and provide it to the homeless via mobile phones. I will deploy this system to diverse set of homeless individuals to better understand how such technologies fit within the social and economic constraints of the homeless community. I expect my research to result in theoretical contributions and guidelines for designing for uncommon users, like the homeless.
\end{abstract}

\section{INTRODUCTION \& MOTIVATION}

The rapid expansion of the mobile computing platform and the accompanying ubiquitous connection to data and communication presents opportunity and consequence for modern society. On one hand, the luxuries of new high-powered personal devices like smart-phones create opportunities for work and leisure where none previously existed; on the other hand, their impact on how we interact socially has consequences for individuals without access.

My research is focused precisely on that second category of users: the individuals and social groups who are considered marginal, who may by choice, by education, or by institutional bias remain at the periphery of the mainstream and importantly, those who remain under-served by many of the technological innovations that have come to symbolize the turn of the millennium. In short, my research is focused on the impact of digital technologies on the urban homeless.

While social scientific and public policy research has long focused on such marginalized communities (e.g. $[3,4,5])$, computing research has only recently begun to consider it as a context for study and intervention (e.g. [2]). Engaging the urban homeless presents a unique and local opportunity to understand the social consequences of technology and to explore the space for successful innovations. As a marginalized and sometimes invisible community, their needs are often overlooked especially as technological advances sweep through the institutions and societies in which homeless individuals and families are struggling to maintain stability and social legitimacy.

I have chosen to focus my research on the urban homeless because they are a diverse community whose individuals may be most affected by technology but for whom technology is often perceived of as an inappropriate luxury. The central question driving my research is: How can mobile technologies empower the urban homeless, impacting their ability to utilize social services, estab- lish stability, and interact as socially legitimate individuals within the broader urban community?

To answer this question, I am building a set of services that integrate community resources - like shelters, employment services, medical, and legal services (among many other) - with contextaware information delivery that presents actionable information via mobile phone. In addition to what might be called institutional information, I am working with the homeless to capture the local expert knowledge used within the community. I am calling this second category of information informal as it is derived from the experience of being homeless, rather than from external assessments of what people who are homeless might need.

In working with the homeless community, I am not looking to "solve" homelessness per se: I acknowledge that social and policy interventions have the most impact for the homeless community. More abundant low-income housing, long-term programs to address education and job training, help in addiction management, and appropriate treatment for mental illness are all first-order problems that continue to demand creativity and leadership. I do, however, argue that thoughtful technological interventions can be deployed as part of the larger effort to redress the inequities of the domestic digital divide that contributes to the marginalization of the urban homeless.

\section{FORMATIVE RESEARCH}

My research to better understand how digital technologies impact the homeless began with two empirical studies; one that developed a more expressive understanding of homelessness as a context for design [6], and a second that examined the unique context of the nonprofit and the organizational and informational constraints unique to the nonprofit world [7].

In the first study [6], several themes emerged as compelling approaches to designing technology for the homeless; however, mobile phones stood out for their unique and valued place in the lives of my study participants. The value of the mobile phones was in part due to the critical functional role the mobile phone played as a device for staying in touch with friends and family, but also for the social role the mobile phone played as a signifier of stability and of social legitimacy.

Most importantly, this study highlighted the degree to which addressing the technology needs of such marginalized communities is not merely a matter of making cheaper technology, but rather of making fundamentally different technology. It points to culturally situated efforts as being more important when addressing the inequities of access - both to technology, and to information mediated by technology - than economically focused efforts.

In my second study [7], I completed observational fieldwork and unstructured interviews in order better understand the work practices at two nonprofit service agencies. The study focused on the 
organizational landscape, the personnel composition, and the use of digital technologies at two agencies who provide different sets of services to the homeless and extremely poor of Atlanta.

In my study sites, the high reliance on a volunteer workforce meant that developing expertise and stability in certain job roles remained a challenge-pointing toward the need for more regimented workflow systems to help enforce procedure and policy across generations of staff and volunteers. However, as a counterpoint, the diversity present across the two nonprofit organizations I studied also showed how mandated, one-size-fits-all systems are insufficient at best and at worst compromise the discretionary powers of case managers.

These two studies form the foundation of my proposed research which looks to leverage the mobile phone as a recognized technology among the homeless and create a set of basic services that amplify relationships the homeless have with each other, with their social support networks, and with the social service institutions upon which they depend.

\section{PROPOSED RESEARCH}

To better understand how mobile technologies might be used within the unique social and economic constraints of homelessness, I am building a system called the Community Resource Map (CRM). Briefly, the CRM will include static information on shelters, counseling services, soup kitchens, employment training, healthcare, etc., blended with dynamic data such as realtime availability of particular resources. The map will blend these information resources to support location-based and context-aware information delivery to mobile phones owned by (or provided to) the homeless individuals I am working with. The system will be deployed to a diverse cross section of homeless individuals over a multi-month period and is aimed at addressing some of the challenges service providers face in collaborating around care provision [7], and at providing the homeless individuals an novel way to capture and share their knowledge with each other.

I will examine the use of the CRM with three complimentary lenses first discussed by Brewer and Dourish [1]: legibility, literacy, and legitimacy.

\subsection{Legibility}

The specific research question I am asking with respect to legibility is: How does access to purposefully designed technology impact how homeless individuals interpret the urban environment and the opportunities available to them? Answering this question will focus specifically on the ways that homeless individuals understand and interpret access to available social services based on their location, their need, and their identity. In designing technology to explore the legibility of space and information, I will be addressing the challenge of information overload faced by the homeless by providing more personalized delivery of information from both social and institutional sources.

\subsection{Literacy}

Under the rubric of literacy, the specific research question I am asking is: How does adding specific capability to a familiar technology (the mobile phone) alter the way the homeless interpret and use that technology as a tool for interacting with society? This question is a response to the desire to understand how to design technologies that scaffold adoption and integration by leveraging a known and relevant platform, the mobile phone. Working from existing literature on literacy, and based on the the specific needs and preferences of the homeless and extremely poor, I will explore alternative representations of information delivered through the mobile phone to both better respond to the user and to extend our understanding of design and interaction techniques for this user community.

\subsection{Legitimacy}

Where legibility and literacy frame my investigation around how technological interventions impact how a social space is understood and acted upon, legitimacy speaks to the socially constructed status of the provision and use of technology. So here, the question derived from considering legitimacy of use is: In what ways do forms of legitimacy influence the legibility afforded by technological artifacts and the literacy of the intended users? This question is meant to provide insight into the situated constraints present when designing technologies for the uncommon user, specifically looking at the different kinds of power relationships that come to bear on their lives.

\section{WHAT I HOPE TO GAIN FROM THE CSCW DOCTORAL COLLOQUIUM}

At this point I have completed empirical work that forms the foundation of my thesis research. I am currently in the process of turning those empirical findings into a robust system that will be used in an extensive deployment. As I move forward, I am looking for feedback on how to balance interventionist research (and the necessarily context specific solutions that go with this style of research) with the broader goals of providing useful advances the field of HCI and CSCW beyond the narrow bounds of my proposed research. I am also keenly interested in hearing in more depth the research areas of interest of my peers and in gaining more exposure within the community as I come closer to entering the job market.

\section{REFERENCES}

[1] J. Brewer and P. Dourish. Storied Spaces: Cultural Accounts of Mobility, Technology, and Environmental Knowing. Int. J. Hum.-Comput. Stud., 66(12):963-976, 2008.

[2] C. Bure. Digital Inclusion Without Social Inclusion: The Consumption of Information and Communication Technologies (ICTs) Within Homeless Subculture in Scotland. The Journal of Community Informatics, 1(2):116-133, 2005.

[3] W. H. Dutton. Transforming Enterprise: The Economic and Social Implications of IT, chapter The Internet and Social Transformation: Reconfiguring Access, pages 375-411. MIT Press, Cambridge, Mass, 2005.

[4] Y. Harrison, V. Murray, and J. MacGregor. The Impact of ICT on the Management of Canadian Volunteer Programs. Technical report, University of Victoria, 2004.

[5] J. Hersberger. Are the Economically Poor Information Poor? Does the Digital Divide affect the Homeless and Access to Information? Canadian Journal of Information \& Library Sciences, 27(3):45-63, Sept. 2002/2003.

[6] C. A. Le Dantec and W. K. Edwards. Designs on Dignity: Perceptions of Technology Among the Homeless. In CHI '08: Proceeding of the twenty-sixth annual SIGCHI conference on Human factors in computing systems, pages 627-636, New York, NY, USA, 2008. ACM.

[7] C. A. Le Dantec and W. K. Edwards. The View From the Trenches: Organization, Power, and Technology at Two Nonprofit Homeless Outreach Centers. In CSCW '08: Proceedings of the ACM 2008 conference on Computer supported cooperative work, pages 589-598, New York, NY, USA, 2008. ACM. 
I am a social scientist and interaction designer starting my fourth year at Georgia Tech. I am in the interdisciplinary human-centered computing program where I am pursuing research that examines the social and practical implications of digital technologies on marginalized communities like the urban homeless. I use qualitative research methods along side interaction design methods in an effort to understand and engage a set of users not normally under the purview of technology research. My approach weaves elements of activist research (in so far as I am working toward social change) and participatory- and co-design (to design with rather than for). I hold the view that humanvalues are expressed through technical systems and artifacts, and accordingly, my aim is to understand the role technology plays as an agent of change within diverse communities and among a plurality of human-values. Currently, I am designing and evaluating a set of interactive services that the homeless can access via mobile phone and that will support the community of homeless individuals who use the system and amplify the resources of the service providers who interact with them.

I came to interaction design via an undergraduate degree in Computer Engineering and seven years of experience as a practicing interaction designer. While completing my degree, I quickly realized that for me, the interesting part of the equation was the human part. I wanted to better understand and design technology for people, focusing on the capabilities and desires of real people using real systems. After finishing my bachelor degree, I moved to Prague in the Czech Republic and began my career as an interaction designer with Sun Microsystems. During my seven years at Sun, I carefully endeavored to bring meaningful and natural technology experiences to end-users and, just as importantly, relay the vastly diverse values end-users have to the development and management organizations that built the technology. My decision to leave industry and pursue a my Ph.D. at Georgia Tech came after realizing that my core interests were in the research that drove design, and in developing the techniques and methods that put designers (and entire production organizations) in touch with what their users want, how they adopt and adapt, and ultimately, how different cultures (geopolitical, professional, lay) negotiate meaning through technology. These interests have motivated my current research as I explore the use of technology amongst a distinct group of users often made invisible in modern society. 


\section{Christopher A. Le Dantec}

Georgia Institute of Technology GVU Center, TSRB, 85 5th St. NW

Atlanta, GA. 30308 ledantec@cc.gatech.edu +1404319 9840

www.cc.gatech.edu/ ledantec

\section{Education}

Georgia Institute of Technology, College of Computing, 2006-2011 (anticipated)

Ph.D. Candidate in Human-Centered Computing

Dissertation: Community Resource Map: A Mobile System and Design Exploration in Support of the Urban Homeless

Committee: Dr. W. Keith Edwards (advisor); Dr. Carl DiSalvo; Dr. Rebecca E. Grinter; Dr. Wendy Kellogg;

Dr. Elizabeth D. Mynatt

University of Arizona, College of Engineering, 1995-1999

Bachelor of Science; Computer Engineering, May 1999

\section{Peer-Reviewed Publications}

1. C. A. Le Dantec. Situated Design: Toward an Understanding of Design Through Social Creation and Cultural Cognition. In C\&C '09: Proceedings of the 7th ACM SIGCHI Conference on Creativity \& Cognition, Berkeley, CA, October 27-30 2009.

2. C. A. Le Dantec and E. Y. Do. The Mechanisms of Value Transfer in Design Meetings. In J. McDonnell and P. Lloyd, editors, About: Designing - Analysing Design Meetings. Taylor and Francis, 2009.

3. C. A. Le Dantec, E. S. Poole, and S. P. Wyche. Values as Lived Experience: Evolving Value Sensitive Design in Support of Value Discovery. In CHI '09: Proceedings of the 27th international conference on Human factors in computing systems, pages 1141-1150, New York, NY, USA, 2009. ACM

4. C. A. Le Dantec and E. Y. Do. The Mechanisms of Value Transfer in Design Meetings. Design Studies, 30(2):119-137, March 2009.

5. E. S. Poole, C. A. Le Dantec, J. R. Eagan, and W. K. Edwards. Reflecting on the Invisible: Understanding End-user Perceptions of Ubiquitous Computing. In UbiComp '08: Proceedings of the 10th international conference on Ubiquitous computing, pages 192-201, New York, NY, USA, 2008. ACM.

6. C. A. Le Dantec and W. K. Edwards. The View From the Trenches: Organization, Power, and Technology at Two Nonprofit Homeless Outreach Centers. In CSCW '08: Proceedings of the ACM 2008 conference on Computer supported cooperative work, pages 589-598, New York, NY, USA, 2008. ACM.

7. C. A. Le Dantec and W. K. Edwards. Designs on Dignity: Perceptions of Technology Among the Homeless. In CHI '08: Proceeding of the twenty-sixth annual SIGCHI conference on Human factors in computing systems, pages 627-636, New York, NY, USA, 2008. ACM.

\section{Refereed Workshop Papers}

8. C. A. Le Dantec. Legitimacy at the Outskirts: Categories, Use, and Adoption in Marginal Communities. In UbiComp '09: Workshop: Globicomp, Orlando, FL, September 29-October 3 2009. ACM Press.

9. C. A. Le Dantec and E. S. Poole. The Value of Pictures: Photo Eliciation Techniques for Engaging Users. Position Paper: CHI Workshop: Values, Value and Worth. April 2008.

\section{Refereed Panels}

10. mc schraefel, P. Andr'e, R. White, D. Tan, T. Berners-Lee, S. Consolvo, R. Jacobs, I. Kohane, C. A. Le Dantec, L. Mamykina, G. Marsden, B. Shneiderman, P. Szolovits, and D. Weitzner. "Interacting with ehealth: towards grand challenges" for hci. In CHI EA '09: Proceedings of the 27th international conference extended abstracts on Human factors in computing systems, pages 3309-3312, New York, NY, USA, 2009. ACM. 


\section{Magazine Articles}

11. C. A. Le Dantec. Feature: Life at the Margins: Assessing the Role of Technology for the Urban Homeless. interactions, 15(5):24-27, 2008.

12. C. A. Le Dantec. What Technology Says. Ambidextrous. To Appear Fall 2009

\section{Invited Talks}

13. "Fighting the Digital Divide." Community Voice Mail annual conference. Seattle, WA. 3 October, 2008.

14. Seminar: "Technology and Homelessness: Touch Points and Values" University of Washington. Seattle WA. 2 October, 2008.

15. "HCl practice in Prague." IFIP TC-13 Annual Meeting. Prague, Czech Republic. 2 March, 2002.

\section{Grants \& Honors}

NSF HCC Small Grant (Advisor Keith Edwards, PI)

College of Computing Outstanding Graduate Research Assistant Award. 2008-2009

Microsoft Research Graduate Fellow, 2009-2011

Foley Scholar, 2008-2009

School of Interactive Computing , Ph.D. Student Research Excellence Commendation, 2008

Best of CHI 2008, for Designs on Dignity: Perceptions of Technology Among the Homeless

\section{Membership \& Service}

ACM \& SIGCHI Member, 2001-Present

Planning Committee and Poster Session Co-curator, Computing at the Margins Symposium Spring 2009

Reviewed for International Journal of Human-Computer Studies, 2009

Reviewed submissions for CHI, CSCW, UIST, \& UBICOMP, 2006-Present

Student Volunteer @ CHI08 in Florence IT.

\section{Research Projects}

Homelessness \& Technology

Summer 2007 - Present

I am currently involved in a series of studies of homelessness and technology. This work began with a qualitative study of Atlanta's local homeless population and has continued with fieldwork investigating work practices within nonprofit service agencies. I am currently designing of a set of information sharing services that aggregate information available in the community and provide it to the homeless via mobile phones.

inSpace

Fall 2006 - Spring 2008

The focus of the inSpace project is to build technology with social affordances to better enable fluidity during collaborative activities. In contrast to much of the work in so called "smart" meeting spaces which has focused on moving agency into the supporting technology, we worked to re-frame the problem and leave agency with the human actors, creating affordances within the technology to better integrate with social interactions. My role in this project was largely one of project management and design guidance as we mature the software platform in preparation for more rigorous user testing.

Students Advised: Puja Verma, M.S. HCl and Benjamin McMillan, B.S. Computer Science

Research in Design Thinking

Spring 2007 - Fall 2007

I undertook a protocol analysis of two architecture design meetings. The focus of the analysis was to examine how values (personal, professional, aesthetic, functional) were woven into the design activity. The analysis was done through the application of Grounded Theory and resulted in an deeper understanding of how values were exposed in the design meetings. 


\section{Employment Experience}

\section{Sun Microsystems " Prague, Czech Republic \& Sydney, NSW, Australia}

Senior Interaction Designer. Start 10/1999 " End 6/2006

NetBeans was purchased by Sun Microsystems on October 18, 1999. My responsibilities shifted to fulltime User Interface design.

\section{Java SE Deployment, Lead User Experience Designer:}

I was the lead user experience designer for Java SE deployment. I was responsible for the user experience design of all deployment touch points -from the java.com web experience to the rich client Java Web Start deployment platform as well as overseeing the development of integrated deployment experiences that promoted Sun and Sun business partner products. Orchestrating work across several functional groups, I delivered thorough deployment solutions that focused on delivering seamless experiences for users moving from web, to rich client.

User Interface Review Board, Brand and Visual Design Lead:

I was the principle visual design and brand compliance designer on the User Interface Review Board (UIRB). The UIRB started out as a gateway to help ensure Sun's administration applications met baseline usability and consistency requirements. It became a very successful group within Sun and was quickly recognized as a fundamental piece for ensuring quality user experience and brand expression. As part of the team that was first to implement Sun's revised visual identity, I was invited to join the UIRB and develop the brand review process as well as provided visual design support for products that lacked dedicated access to a designer.

Project Buz [sic, thoughout], Lead Interaction Designer:

Project Buz was a look at ad-hoc collaboration. I was involved as the lead designer exploring how to take the project from the laboratory to the customer. Project Buz focused on integrating many of the established communications services already present and augmenting them with improved peripheral awareness, integration between applications and communication channels, and a shifted focus from how we communicate to with whom and to what end we are communicating.

NetBeans IDE, Interaction Designer:

My responsibilities started with a range of functional and interaction design for the NetBeans Java Integrated Development Environment (IDE). I created and tested prototypes, authored more than a dozen complete interface specifications, ran two to three usability studies each year, and researched current best practices for design and customer research. My last contribution to NetBeans was a complete update and rewrite of the UI Styleguide.

As the first UI designer to work in the Prague office, I was instrumental in bringing a new level of user centered focus to a group of engineers who had no prior experience with methodologies like user centered design, usability studies, interview and heuristic evaluation. This was the first major success I achieved as a UI designer in the Prague office.

http://www.netbeans.org

\section{NetBeans "Prague, Czech Republic}

Infrastructure Design Engineer. Start 6/1999 " End 10/1999

After completing my degree at the University of Arizona, I moved to Prague, Czech Republic, to work for a Java tools startup company. My initial responsibilities included designing and implementing company infrastructure as the chief network architect, designing the user interface for the company's web storefront, and sitting in as a technical writer, customer support representative, and web content developer as the different needs arose.

\section{Microsoft Research " Redmond, WA}

Program Manager Intern. Start 5/1998 " End 8/1998

I was responsible for developing application and user interface specifications for a network collaboration and distance learning application. I worked on an extension that would facilitate "town meeting" scenarios. The only remaining vestige of work I was involved in is Hutch World, found at the MSR web site: http://research.microsoft.com/scg/ 


\title{
Designs on Dignity: Perceptions of Technology Among the Homeless
}

\author{
Christopher A. Le Dantec \\ W. Keith Edwards \\ GVU Center and School of Interactive Computing \\ College of Computing \\ Georgia Institute of Technology \\ Atlanta, GA, USA \\ \{ledantec, keith\}@cc.gatech.edu
}

\begin{abstract}
Technology, it is argued, has the potential to improve everyone's life: from the workplace, to entertainment, to easing chores around the home. But what of people who have neither job nor home? We undertook a qualitative study of the homeless population in a metropolitan U.S. city to better understand what it means to be homeless and how technology - from cell phones to bus passes-affects their daily lives. The themes we identify provide an array of opportunities for technological interventions that can empower the homeless population. Our investigation also reveals the need to reexamine some of the assumptions made in HCI about the relationship people have with technology. We suggest a broader awareness of the social context of technology use as a critical component when considering design innovation for the homeless.
\end{abstract}

\section{ACM Classification Keywords}

K.4.2 Social Issues: Miscellaneous

\section{Author Keywords}

Homeless, Urban Computing, Social Computing, Value Sensitive Design, Diary Study, At-risk Populations

\section{INTRODUCTION}

The HCI community is currently going through a period of change as the problems it considers and the contexts it investigates move beyond the western, corporate world. For example, Chetty and Grinter have begun to outline the methodological implications of working in the Global South [7]; Wyche et al. examine different techniques for investigating technology use in the home [39]; and DiSalvo and Vertesi have begun to bring practitioners and thinkers from outside the HCI community together to consider urban experiences through the lens of emerging technologies [12]. But in exploring new social contexts, we need to reexamine our assumptions about the relationship people have to

Permission to make digital or hard copies of all or part of this work for personal or classroom use is granted without fee provided that copies are not made or distributed for profit or commercial advantage and that copies bear this notice and the full citation on the first page. To copy otherwise, or republish, to post on servers or to redistribute to lists, requires prior specific permission and/or a fee.

CHI 2008, April 5 - 10, 2008, Florence, Italy.

Copyright 2008 ACM 1-59593-178-3/07/0004...\$5.00. technology. One such context that has not been explored in any depth within HCI, and challenges us to consider how we account for the social environment, is technology use among the homeless.

The goal of our research is to characterize perceptions of technology among the homeless, to identify the unique needs of the homeless when considering appropriate technological interventions, and to describe the challenges in both working with, and designing for, the homeless population. Our approach was informed by value-sensitive design [15, 16]. We undertook a qualitative study of the homeless community in a large metropolitan city in the United States. Our study involved individuals who were currently homeless, recently homeless and living in transitional housing, as well as those who were on the cusp of becoming homeless due to job loss or prolonged periods of economic hardship. We interviewed 13 participants to gain insight into their relationship with technology.

In this paper we address some of the misconceptions held about the homeless population, in terms of its demographic make-up as well as its informational needs. In presenting our findings, we show a number of themes present in the lives of the homeless individuals in our study, and we unearth tensions that exist between the needs of this population and assumptions the HCI community has about how people relate to technology, the urban environment, and their social networks. Our contributions are an understanding of how homeless people currently perceive technology, indications of their information and communication needs, and a characterization of the classes of technological interventions that could be effectively designed for the homeless community.

\section{RELATED WORK}

\section{A Portrait of the Homeless}

There is no single "homeless community." Many factors contribute to being homeless, making it difficult to derive a complete and accurate picture of the homeless population. The U.S. Government defines homelessness in the Stewart B. McKinney Acts, 43 U.S.C. \$11201, et seq (1994) as any person who (as quoted in [26]):

lacks a fixed, regular, and adequate night-time residence and... has a primary night time residency that is:

(A) a supervised publicly or privately operated shelter 
designed to provide temporary living accommodations...

(B) an institution that provides a temporary residence for individuals intended to be institutionalized, or

(C) a public or private place not designed for, or ordinarily used as, a regular sleeping accommodation for human beings.

While the McKinney act definition of homelessness is clear, it remains difficult to derive a complete picture of the homeless population [37]. Homeless census activities focus on counting the number of individuals housed in emergency and long-term shelters, transitional housing, and low-rent, single-room hotels [38]. Ironically, the most visible and socially stigmatized members of the homeless communitythose who live outside the support of the social system-are also the most difficult to capture information about.

Through the 1980's, 1990's and early 2000's, despite periods of strong national economic growth, the homeless population in the U.S. either grew or remained steady [34]. At the same time this population was growing, it was also becoming more diverse; the makeup of the homeless community in the U.S. has evolved from being mostly single males from the laboring class to include an increasing number of women and families, the majority of which are headed by a singleparent female [3].

\section{Causes of Homelessness}

In contrast to the causes of single-male homelessness (such as addiction disorders and mental illness [34, 36]), homeless families are more likely driven to homelessness due to economic hardship [3]. They typically come from the "extremely poor" who live below $50 \%$ of the poverty line [37]. These homeless families face challenges in getting off the streets that are less pronounced or absent among the singlemale homeless population such as domestic violence, health problems, and managing care for young children [11].

Despite the variety of factors contributing to homelessness, poverty and the availability of low-income housing are the most critical factors shared by most of homeless population. In some urban areas the lack of affordable housing can preclude even the working poor from maintaining a residence; individuals have jobs and are "productive" members of society but are unable to secure housing [18].

Studies of homelessness in other industrialized countries show that a number of contributing factors to homelessness are consistent throughout the industrialized world. When comparing homeless and domiciled poor in Madrid, Muñoz et al. described traits common to both sides of the Atlantic: low education levels, high unemployment rates, and pervasive mental and physical health problems [27]. Likewise, in a study of the London homeless population, Radley et al. addressed the complex relationship homeless individuals have with their urban homes [31]. The multi-faceted causes of homelessness and the complex interaction with the urban environment described by these studies were all present in interactions with our participants.
Technology \& The Homeless

The factors that disadvantage developing nations are also present among the homeless population in industrialized nations and affect the relationship of this population with technology; lower levels of education and literacy restrict access to information, a lack of economic independence restricts access to computers and Internet resources, and limited access to training hinders uptake of digital technology when it is made available. These factors converge, leading to a situation of economic poverty along with what has been called information poverty - a dearth of access to useful information resources [6].

The social environment of the homeless population has also been attributed as a factor in information poverty. Snow and Anderson argue that the socialization that occurs on the streets does not provide access to the necessary resources to get off the streets [35]. Likewise, interviews with New York City homeless describe a transformation in which the social connections a homeless person has that would enable them to get off the street are gradually replaced with the social connections necessary to survive on the street [10]. In this regard, information poverty can be understood additionally as a social phenomenon that inhibits access to useful information resources.

Based on this view of information poverty, one might aim to provide design innovations - both social and technicalthat allow homeless persons access to the information that they are lacking. However, whether this claimed state of information poverty exists is debatable. Hersberger, for example, questions the assumption that individuals who are economically poor are also information poor [24]. She found that instead of perceiving themselves at an information disadvantage, "If anything, [those interviewed] felt they might be suffering from information overload due to the propensity of service providers to share information [about relevant social programs] with them" [24]. Hersberger questions "how valuable and useful an information-seeking tool the Internet would be in the everyday lives of homeless families" given they already feel overwhelmed by information received primarily through caseworkers and word-of-mouth communication [23, 24].

The implication in Hersberger's work is that it is not simply access to technology and information that determines integration with society. Information is reaching the homeless community in overwhelming volumes, yet social factors discourage acting on that information. The specific constraints placed on the homeless population put a higher premium on the larger context in which information is situated [1]. "Simply providing information on available jobs is not always enough. If public transportation does not stop near the place of work, then a list of jobs might be useless information" [26]. In another example, Hersberger notes that homeless people who attended a mandatory meeting on improving credit history were largely disengaged from the information because it addressed strategies for managing money and did not address their immediate problem of first finding a source of income [24]. Ultimately, these examples boil down to the importance of not merely the availability of information, but 
ensuring that information is sensitive to the social context of those who receive it.

\section{METHODOLOGY}

Working with the homeless population has pronounced risks and ethical considerations [13]. As we developed our plan for this study, our first thought was to immerse ourselves with the homeless population "in the wild"-in the parks and public spaces they inhabit during the day. It became quickly clear that this strategy would exacerbate the risks to both researcher and subject. Instead, we worked closely with two metropolitan outreach groups to develop our approach and mediate contact between ourselves and the homeless community.

We were acutely aware of the imbalance of power between ourselves and the homeless persons in our study. Mitigating the social and economic differences and the sense of authority that comes with being a "researcher" were important for establishing trust and negating any sense of coercion participants may have felt. We were also sensitive to the different threshold for what constitutes non-coercive remuneration for participating in the study. We provided participants a choice of a \$20 store gift card or a \$20 public transportation card. The choice and dollar amount were reviewed by caseworkers and deemed fair and appropriate.

After careful consideration, we decided to use a PhotoElicitation Interview (PEI) [8, 9]. PEI studies are a form of diary study [33] where participants are provided with a camera and instructions to take photos of their choosing. This form of inquiry is similar to Cultural Probes, though the focus is on facilitating the interview process rather than design per se [17]. The benefits of the PEI method are that it disrupts power dynamics, enabling the participant to retain more control over the interview; it enables deeper reflection on the topic by providing more context and peripheral data; and it provides opportunities for the participant to defamiliarize themselves with familiar aspects of their lives $[5,9,22]$. This form of study has been used by other researchers outside the HCI context (such as Radley, et al's study of the London homeless population [31]) and was well suited to our study design.

Staff at the outreach centers introduced us to the community, providing us a chance to give an overview of the study goals, make ourselves available for questions, and generally become known to potential participants. By having staff introduce us, we were able to mitigate skepticism and be more effective in explaining our desire to learn more about the everyday needs and activities of the individuals we were recruiting for the study. We also relied on staff to help us identify individuals for whom participation in our study may not have been appropriate due to mental health issues. Participation in the study was on a volunteer basis and we were careful to overstate the independence of participating in our study and receiving services from the outreach center.

To gain access to a diverse cross section of the homeless community, we chose outreach centers that served different segments of the homeless population. The first center focused on providing life-assistance to prevent homelessness in the form of food, rent, and utility assistance programs. The clients we casually observed at the center were just as likely to be women, often accompanied by their children, as single men. They were part of the working poor and used the services as a way to augment short term needs. An important detail about the first center was that it structured its services such that clients could only return to request further aid once every 90 days. The second organization focused on helping homeless individuals dealing with drug and alcohol addiction, mental illness, and physical disability. Their programs were built around daily Narcotics and Alcoholics Anonymous (NA and AA) meetings. Daily lunch was also served to current clients and program alumni. The daily contact clients had with the second center became an important factor in the return rate for collecting cameras and conducting interviews.

\section{Study Design and Analysis}

Our study was broken into three meetings that took place over a period of three weeks. All direct contact with study participants took place at one of the two outreach centers.

Meeting 1: In the first meeting we provided a disposable camera and asked the participant for their preference between the store gift card or public transportation voucher. We explained that they would receive the incentive at the beginning of the third, and final meeting. The camera we provided had a modified case that included instructions on camera use, suggestions on what to document with the camera and a reminder to return the camera after two weeks. The instructions for what to photograph read:

- Take photos of places or situations where you needed help.

- Take photos of of the things you use: telephones, buses, radios, televisions.

- Take photos of your daily activities.

- There is no such thing as a bad photo. This is your life, your story.

We intentionally did not mention the word "technology" in the on-camera instructions. Instead, we briefly discussed different forms of technology during the first meeting. To encourage a broad understanding of technology, we told participants an apocryphal story about the impact on the working poor and homeless communities caused by a recent move from token-based public transportation to electronic-cardbased transportation. The point of this story was not to focus ire on a changing public service, but to introduce the many manifestations technology has in daily life. Beyond this brief explanation of technology, we intentionally left the photo task open ended to encourage self-reflection without the imposition of too many rules. Finally, we established that the camera was to be returned to the same outreach center where it was handed out.

Meeting 2: After two weeks, we returned to the outreach center and collected cameras from the participants. As we collected the cameras we scheduled interviews for the following week to be held at the outreach center.

Meeting 3: At the beginning of the final interview, we provided the gift card to the participant and asked them to re- 
spond to a basic demographic survey before we discussed the photographs. The decision to not seek any contact information and to delay collecting basic demographic information until the final meeting was specifically to provide an extended period for participants to opt-out of the study without feeling regret or distress in having signed up and given us their personal information.

The interviews we held were open ended and constructed around the events depicted in the participant's photos. We began each interview by letting the participant talk about their photos at their own pace. Participants were then asked to specifically talk about technology including the use of cell phones, computers and the internet, and transportation. We also asked all participants to describe their social networks by way of how they stayed in contact with friends and family, how they discovered different services such as shelters, addiction management, and job placement, and how they managed their daily schedules. We were careful to use information in the photos to frame how we posed these questions; in some cases questions were asked in response to specific photos while in others, questions were asked in the absence of photographic context (e.g. Why didn't you take a photo of $x$ ?).

The themes that motivated the interview-technology use and perception, social networks, and information management-formed the basis for coding the transcripts. As the analysis progressed, we recognized new themes that emerged from the data though the focus remained on how technology informed various aspects of our participants' lives. Two researchers coded the data, and discussed the findings that emerged. The results we report here were those that consistently appeared across our participants, except in a few extraordinary cases which we are including to illustrate the diversity in the homeless demographic; we felt that these unique examples shed more light on the range of experiences.

\section{Overview of the Participants}

In total we had 28 participants, 14 from each outreach center. Out of that total, 13 participants fully completed our protocol, meaning that 13 final interviews were held. The camera return rate between the two locations was vastly different. From the first center only one camera was returned, one week late and without contact details for us to follow-up. At the second center, all cameras were returned and interviews held with all but one participant.

As a result of not collecting demographic data prior to the interview, we did not have documented details about the individuals who did not return. Anecdotally, they were more often women and several had expressed that they were actively seeking employment.

Of the participants we interviewed, 11 were male and two female, all between the age of 46 and 55 years old. Ten of the participants identified as African-American and three as Caucasian. The level of education ranged from the 4 th grade (about 9 years of age) to a two- or four-year college degree, with the center of the curve having completed high school or their GED (high school equivalency test). The average time spent living on the street was 36 months, with a high at 10 years and a low at six months. At the time of the study none of the participants were living on the street. They all had some form of housing, either through a local shelter or in a dormitory at a transitional housing facility; however, the photos they took and their responses during the interview were reflective of periods when they were not situated in housing.

\section{FINDINGS}

Through the interview process and subsequent data-driven analysis, several themes have emerged in the relationship between the homeless population and various types of technology. This section discusses these themes and points toward needs of our study participants that suggest opportunities for successful technological interventions.

\section{Staying Connected}

The first theme was the importance of staying connected to family members and friends during spells of homelessness. P17 talked about being on the street, "You stay in that depressing state where you feel as though giving up. You know it wouldn't be a problem just to give up out there. That's how you think and stuff so... I have people I talk to on a daily basis, you know, they keep me...motivated and stuff, and make me realize, you know, that it's going to be okay." P27 was more emotional when talking about staying connected, “It's one thing being homeless but it's another thing... disappear[ing] from the face of the earth. And that's the biggest danger for homeless people. That's the hardest thing to manage, is when you get disconnected."

Many of the participants came from places other than their current urban home and keeping in touch over distance was something they worried about. There was a real concern that something could happen to loved ones and they wouldn't know it; as P27 put it, "Somebody can be gone, someone in my life can be gone, my loved one, and they don't know how to get to me." The sense of disconnection from an extended social circle was a considerable source of stress and was remarked on by several of the participants throughout the interviews.

P25 became homeless as a result of hurricane Katrina. He described the time since Katrina: "these last years have really been a really rock bottom, no I mean a really rock bottom... You know when you never had no other home address, you know, and you come in somewhere else you gotta move [exchange] your home address for a homeless shelter." Prior to Katrina, P25 lived with his mother in New Orleans, Louisiana, and in the course of his family evacuating, were split up; he ended up in Houston, Texas, while his mother ended up in Austin, Texas. He went on to say, “I haven't seen my momma since Katrina [2005]... When I was in Houston, the Red Cross... had a system to put our year, our date and the last address... Where ever my mother was at, that's how they tracked her down. Though when I called her she was on the voice thing... I never talked to her I just heard her voice on the thing." Displacement, becoming newly homeless, and the affect of losing contact with his immediate family all converged at once. 


\section{Synchronous v. Asynchronous Connections}

The difficulty P25 had in trying to contact family in the aftermath of Katrina is only one aspect of the relationship our participants had with telephones. Although voice telephony is often conceived of as a synchronous communication technology, this was - in many cases - not a common mode of use for our participants. All of the participants had voicemail accounts through local organizations. These accounts were meant to provide a stable number of contact and aid in job searches and managing appointments or other personal business. The difficulty for a number of participants was in accessing their voicemail, leading to a decidedly asynchronous style of communication when using the telephone.

For access to phones and to check voicemail, participants used free phone services provided by local organizations. P28 noted, "I have to go to Project Connect [to use the phone], and I don't go there that much. I go to [the hospital] but you gotta stand around and wait for the phone." Many of the participants in this study preferred the free phones at the main metropolitan hospital. This service was very valuable to the participants in our study; however, the use of the telephone became part of a larger daily activity of traveling to the hospital, waiting in line and finally using the phone. Participants cannot rely on being able to use the phone as they may not go to the hospital or once there, they may not have the time or opportunity to use the phones. This constraint frustrated staying in contact with family members, and imposed uncertainty in time sensitive communications such as job hunting or responding to opportunities for aid.

\section{Mobile Telephony}

The preferred way to maintain a stable connection to family and friends for many of the participants in the study was through a cell phone. P17 talked about the utility of having a cell phone, "That [a cell phone] would have been real useful 'cause there's nothing like keeping in touch with your family." For a number of participants, cell phones were the only stable connection they had to their pre-homeless liveseight of the thirteen participants $(61.5 \%)$ currently had cell phones. P22 noted that a friend continued to pay her cell phone bill because, "that's the only way [my son] had to get in touch with me."

Long and troubled histories of drug and alcohol addiction had caused some of our participants to sell personal items. However, when we specifically asked them if they would have sold their cell phone (if they had been able to have access to one), they responded that no, they would not sell the phone for money. P19, who had taken a photo of the pawn shop where he had sold his possessions, specifically noted that he would not sell a cell phone, "No I would have kept it. That's one thing, well, one thing of numerous things, that I would have [kept]." This sentiment echoed similar feelings among our participants about the unique value of a mobile telephone.

However, cell phones were not without problems. The difficulties with cell phones for the participants in this study were the ongoing cost, the need for access to power to recharge the phones, and the inevitability of theft when living in and out of shelters. P16 responded that he had a cell phone but, "[the] cell phone started costing me more than they were worth." Participants desired cell phones that were on pay-asyou-go, or prepaid, plans instead of fixed monthly contracts; P17 elaborates "if I got 10 or 15 dollars or something, I put 10 dollar worth of minutes on it [prepaid] so I could use it."

For P28, cell phones were useful and a tool that he would exploit as he had access to them. He talked about using phones he found until the batteries died; "I had a cell phone until the battery died. . . actually I found one in the train after that... and I kept using it because the person never did call to see if they could try to find it. It was a Nokia. Eventually that died down and the service ended and I had to throw that away, that was a good phone." Here P28 used the phone to call out but it did not function as a stable point of contact. This opportunistic use of any found or available resource was summed up by P17, "I mean being on that street, you're taught to, you know everything is valuable to you on the street."

\section{Identity Management}

Homeless persons interact with a number of different social groups and identity management was a key aspect of their lives [19]. For participants in our study, different forms of identity management came out through their use of technology and social institutions. Some forms of identity management were used when facing close family or friends while others were employed as defense against the social stigma of being homeless.

Identity management took both technology- and non-technology-focused forms. For example, on the non-technologic side, identity management appeared in how participants managed their physical appearance. P25 talked about mapping out where to go to take showers and do laundry, "[just] cuz you're homeless, that don't mean you got to look homeless or smell homeless." Likewise, P26 was very conscious about his appearance and the fact that he had to present himself well: "I always find me someplace I can take a bath or take a shower or wash up. Because you know I like to keep clean, I'm always facing peoples, I didn't want to stand around in all dirty clothes."

This desire to not appear homeless presented logistical challenges. Some shelters do not have storage or limit the amount of personal affects a resident may bring in. To address this, outreach centers will offer "clothes closets" where their clients can store personal affects. P17 talked about managing the logistics of storing clothes at one location while staying at another: "If you stayin in the shelter see, what I'm sayin', you carry those clothes around, you come here [to the clothes closet] every day get a change of clothes you know, to take back with you to the shelter."

Technology-centered forms of identity management also appeared prominently in our study. In addition to being desired for staying in touch with extended family, the cell phone was also a valuable identity management tool for the social value it provided [35]. P27 was especially sensitive about who of his extended friends he would tell about being homeless. For P27 it was an issue of pride that he was going through a difficult time but, "they know if I got my cell phone I must 
be doing alright." So more than providing communication functions, the cell phone provides a connection to the larger world as a potent social symbol.

P28 used more tools in identity management. He regularly used the Internet at the public library and explained, "I have a mySpace account... I get in contact with friends that have an account with them." He was also careful about not telling his mother about the fact he was living on the street: "I'd just go visit her, I wouldn't tell her where I was living at." Such stable, technology-mediated forms of communication provided an important resource for our participants in managing their own presentation of self, and mitigating the social stigma of homelessness.

\section{Access to Information, Social Networks}

The social network was the primary mechanism participants in this study used to navigate the world around them. As noted above, maintaining a social connection with a larger world is critical for individuals dealing with homelessness. These connections are immediately sought out on the street, as much for survival as to get plugged into support infrastructure. P17 was quick to point out that when living on the street, "you try to get with people you know. You stay around people you know." Likewise, P27 pointed out his willingness to help friends on the street, "I will turn her [a hypothetical, newly homeless person] on to the good things that I learned. . I will give this information to other people." Safety in numbers was a recurring sentiment that illustrates the visceral need homeless people have for finding friends they can trust on the street.

Once they have been accepted into social programs, the focal point for information becomes the caseworker. All but a couple of our participants took a photo of their caseworker or main contact at hospitals or outreach centers. The central role of the caseworker in the lives of our participants is consistent with Hersberger's description of social networks in homeless populations as being built around the social institutions that provide support [25].

The reason the caseworker was the primary contact was not immediately clear, though a combination of factors is most likely the case. First, many social services require a letter of reference to be considered for enrollment. These letters are used to confirm medical conditions, regular participation in addiction treatment, and other eligibility requirements. Second, the capabilities of the participants were extremely varied. Two of the participants were illiterate, while others used computers regularly and effectively. Several of the participants, however, suffered from various mental dissabilities complicated by a lifetime of homelessness and drug addiction. For many of these individuals, the self direction and discipline needed to seek out services and navigate the system on their own is itself a challenge. They genuinely need the caseworker to explain the system, setup the appointments, and fill in the forms.

\section{The Digital Divide}

Participants varied widely in the use of information technology, effectively resulting in an internal "digital divide" within the homeless community. Three participants, P21,
P22 and P28, were regular computer users at the public library. They all used computers to find services, e.g. P21: "II look up] services, like if I'm in a crunch say, and there's certain medication I can't get through [the hospital]... I go up on the Internet and look [it] up and see if the drug company has any kind of program for it." P28 used online services like Monster.com to try to find work and pointed out that for a number of job placement services it is a de facto requirement to be on-line in some capacity: "Some employers, like [a local employment agency focused on the homeless], ask for your email because they send you stuff."

These three were the exception in this study. Most of the participants had very little, or no, experience with computers, and their reactions when asked about them ranged from bafflement to disinterest. On the other hand, cell phones can be complicated devices, but they offer a number of features that were immediately recognized as useful; P20 did not show much interest in computers but said, "those cell phones, you'd be amazed... they can wake you up... [help keep] your doctor appointments... They can go off and let you know you got appointment tomorrow." The difference in attitude toward cell phones and computers illustrates an important point of inflection in the adoption of technology within this community. So long as there was a perceived benefit, participants were excited about the prospect of using a new technology.

\section{Health and Medication}

All of the participants interviewed were on medication. Several took photos of hospital or pharmacy waiting rooms and they all made comments about remembering to take their pills and managing doctor and counseling appointments.

The challenges this presented varied for each participant. P17 talked about a picture of his room at a transitional housing facility, "that's the back of the door where I keep all my appointments and stuff pasted up so I won't miss my appointments." He had a system so he would see his schedule every time he left his room. P23 had a more proactive reminder, "I gotta nurse, my caseworker, she calls me to let me know [about upcoming appointments]."

P25 had a particularly onerous challenge in dealing with his health issues. His formal education stopped in the 4th grade (about age 9) and he was illiterate. P25 was on a number of medications and was forced to be creative in managing how to took them: "Well, you see by not knowing how to read I go uh, what I do, I know the pills... [and] I got a little sack, a little medicine sack. I have ten bottles of pills so I dump em all out on the bed and... everytime I take one out the bottle, I put the bottle in the sack so I can't go wrong." For P25 to manage his health, he not only needed to devise strategies to work around his illiteracy when taking medications, but also in managing his appointments and providing reminders to himself about what he needed to do on a given day.

\section{Getting Around}

Moving around the city was an imperative for our participants. They often needed to attend addiction counseling to stay in good standing with their shelter's rules, and on- 
going health problems meant regular visits to the hospital for routine exams and prescription refills.

P26 talked extensively about the difficulty in using the new electronic cards on the buses: "you know I had conflicts with the bus driver about, well, they say there ain't no money on your card, and I know my card got money on it. And after he drive off another bus come up and it [the card] works... Sometime it won't be your card, it might be the machine. The machine is not working right and they look at us like your card not working or something and you know [if] we get angry, that ain't gonna help us at all, that gonna make the situation bad... I liked it the old way, the [transit] card was ok. You could ride a train or bus no problem, but this year people thinking all the same and get the hang of it because they might tap in [enter the bus or train] but forget to tap out [when leaving]. So you have to tap out too, see, I ride a train so when I tap out that give me a chance to ride the bus. It has transfer on this card." Further usability issues noted by our participants centered around the ability to know the value on a card (since there is no way to know how many rides remain prior to attempting to use transportation), the sequence of steps to secure a transfer (as transfers to buses and trains are only valid if the card was "tapped out," yet it is possible, likely even, to exit the bus without tapping out).

P26's list of complaints echoes the numerous critiques of other technologies (such as those in [28]) that are wellknown in the HCI community. Yet it is not just the usability problems in the technology that affect homeless persons; the social stigma of being perceived as the homeless person without bus fare is a far more visceral consequence of a poorly designed technology.

\section{DISCUSSION}

We acknowledge that social and policy interventions will have the most impact for the homeless community. More abundant low-income housing, long-term programs to address education and job training, additional help in addiction management, and appropriate treatment for mental illness are all first-order problems that continue to demand creativity and leadership. We believe, however, that thoughtful technological interventions can be deployed as part of the larger effort to reduce homelessness and help the most atrisk members of our society. The challenge for HCI is in considering not just how well a technology will work with respect to usability, but how that technology will be accepted and used by a community. There is no simple answer, but the analysis we have done shows that challenging some of the implicit assumptions held in the HCI community is necessary when considering technology for the homeless.

\section{Designing for Inclusion}

While the themes that emerged from our interviews such as Staying Connected, Synchronous v. Asynchronous Connections, and Mobile Telephony suggest opportunities for technological interventions, we feel it is more important to step back from specific solutions and reflect on the larger implications designing for marginalized communities has for HCI. In thinking about homelessness and technology, it is not enough to consider forms of technology that might be placed directly in the hands of the homeless, we must also consider more broadly how technology in the hands of everyone else impacts the lives of the homeless. These considerations must include a reevaluation of how public spaces become reconfigured through ubiquitous Internet connections and context aware computing; if we, as system designers, do not consciously consider the social impact these new technologies have on non-users as well as users, we will inadvertently set the stage to create an even larger rift between ourselves (as members of the digerati) and the poor, homeless, and otherwise marginalized members of society with whom we share our urban environments.

\section{Urban Computing}

One of the first areas to begin re-calibrating some of HCI's assumptions is in the nascent genre of Urban Computing. Based largely on Augé's notion of "non-space" - a space delimited by uniform access to information, mediated by interconnected technologies rather than physical realities [2]work in Urban Computing has begun to frame explorations of how exploiting wireless technology and the ubiquity of access reconfigure social relationships in public spaces. The defining features of these explorations is to engage the classic divisions of public and private space, to understand how people inhabit public spaces, and to consider how technology can create new opportunities for interaction and reflection within those spaces (e.g. [29, 30]).

At the core of these explorations is the question of how the social landscape changes when our preferred mode of communication is via a technological medium. This change is undoubtedly underway - a glance around the urban environment finds it full of technology mediated communication; however, some efforts in urban computing have not engaged the breadth of social diversity despite encouraging reflection on what it means to belong to the urban social space [30]. It is in this way that HCI is presented with opportunities for inclusion as the homeless share the same parks, train stations, and public squares but are currently excluded from the technology mediated social landscape for the simple reason that the gateways that afford access-mobile phones, PDA's, laptops - are private. Moreover, as we illustrated in our findings, the need to stay connected to the rest of society is a major concern for the homeless, yet as those connections become increasingly mediated by technology, the risk of losing touch becomes greater.

Rather than simply challenging personal notions of public and private space, we could build technology that also challenges social notions of what it means to be connected or disconnected to each other. Bassoli et al. reflected on social computing in this way, enabling a more comprehensive response to what it means to design for the urban environment in a way that included mainstream society as well as marginalized groups like the homeless [4]. Through designing interactions that encourage reflection on the different ways we interact in the physical environment, we can adopt the notion of "non-space" as a basis for creating social awareness of the periphery rather than unintentionally pushing that periphery further out; by recasting some of the technology touch-points of the urban environment as public fixtures, we can create a shared lens through which all par- 
ticipants in that environment can view and respond to each other.

\section{Social Networks}

We have illustrated the importance, and brittle nature, of social networks for the homeless persons in our study; the type of social networks a homeless person maintains has an impact on whether they get off the street [10] and is consistent with Granovetter's notion of the strength of weak ties [20]. In trying to strengthen and diversify those weak ties, we are presented with an opportunity to augment the co-located social networks of the homeless population with technology, furthering an agenda of designing for inclusion.

Foth's study of Australian inner-city social networks describes a slightly different community that has similar needs to the urban homeless [14]. Foth contrasted the shared "common purpose, goal, interest, or support need" present in on-line communities to the absence of those traits within co-located communities. He pointed out that co-located communities are built around the serendipity of unplanned interactions and not around community members seeking each other out based on shared values.

While Foth makes a strong distinction between communities built around shared goals versus those built around colocation, the homeless community is not adequately served by trying to strictly adhere to that division. The homeless have shared goals such as finding shelter, food, and employment as well as shared needs like addiction management and healthcare. At the same time, the serendipity of word-ofmouth communication that arises out of co-location plays a critical role in spreading information about services within the community. Furthermore, the nature of social interactions in the homeless community is marked by an intense preference for the personal. The expressed desire of the homeless in interacting with social workers is to know they have that person's full attention; phone conversations are not preferred as they do not provide an affordance for measuring attention [25]. A shared sense of urgency and being treated with dignity are important ways a homeless person identifies a "friend" [26].

Mediating these interactions with technology may not be the best way to preserve dignity and the sense of shared urgency. Technology solutions for the homeless need to bear in mind the critical factor personal relationships play in their lives. A successful intervention would preserve, or enhance, the personal contact time with caseworkers and supportive groups as well as enable homeless persons to share experiences and establish new connections. In this way, the potential for augmenting social networks with technology lies in enriching and multiplying the number of connections the homeless person has to social institutions as well as other members of the community who are attempting to get off the streets.

\section{Affordances for Planning}

A third avenue for addressing inclusive design presents itself in how we structure technology around commercial transactions. For participants in our study, managing the costs of communication and travel is a priority. As an example, just as teenagers prefer SMS messaging because of its predica- ble cost [21], participants in our study made communication decisions based on their ability to predict cost.

Pre-paid cellular services allow the homeless to do some planning and cost control. However, the economic model of pre-paid cellular service in the U.S. is problematic for this population. Purchased minutes expire after as little as 30 days and phone numbers that become inactive can be reclaimed by the service providers after 90 days. When the terms of prepaid cell phones are combined with irregular incomes it puts the homeless at risk of losing their phone number and thus the stable contact point with their larger social network.

In a similar vein, the apocryphal story we used as a catalyst for thinking about technology was not entirely without merit. The local transportation system had recently made a switch from using tokens for ride fare to an electronic-card based system. The cards come in two varieties, a permanent plastic card that costs five dollars, or disposable paper cards that cost fifty cents. The additional cost of the cards is only one factor in the practical consequences. With tokens, it is easy to keep track of how many rides remain. With the electronic cards, in order to know the remaining balance on the card, it must be placed near a reader. This means a user does not know how much credit is left until trying to board public transportation.

The cumulative effect of these two systems is an inability to plan ahead with budgeting for communication and public transportation. In the case of cell phone service it affects a homeless person's ability to stay connected to a vital social network and in the case of public transportation it complicates travel planning and creates situations of public embarrassment when attempting to board public transport with a card that has been used up.

\section{Challenges in Reaching the Homeless Community}

We need to continue to work with the homeless community to develop a more nuanced understanding of their needs. However, the unfamiliarity of this community within $\mathrm{HCI}$ serves to exaggerate some of the difficulty. The challenges we experienced in conducting our study are consistent with the known difficulties of working with the homeless [34], but we hope to better inform HCI research with the homeless community by discussing our experiences from this study.

A challenge that we were faced with was in enabling consistent contact with members of the homeless community. We were initially surprised at the vastly different camera return rates between the two outreach centers we worked with. We had expected a partial return rate from both centers, not the all-or-nothing response we received. Contributing to our surprise was that the all-or-nothing difference occurred despite an incentive of $\$ 20$ to complete our protocol. Had we increased the incentive, we may well have garnered a higher return rate, but such a strategy poses a tension with the requirement that studies involving at-risk individuals not be coercive (is a study whose compensation is enough to distract a homeless participant from job hunting effectively coercive, and ultimately counter productive?). On the one hand the low return rate at the one center reassures us that 
the remuneration was not coercive, but on the other, it underscores the challenges of working with a community whose daily struggles make planning ahead difficult, if not impossible.

By looking at environmental factors that contributed to the difference in camera return rates, we concluded that the operational differences at the two centers played a critical role. The infrequent contact of once every 90 days that participants had with the first center meant that their presence at the center was not habitual and it may have been easier to forget or lose interest in returning to complete the study. Conversely, the daily contact participants had with the second outreach center meant that they did not need to break routine in order to continue participation in the study.

Care should also be taken when considering the logistics of any study. The logistics of our study placed a fair amount of responsibility on the participants and in looking back, we could have made better use of contact information and personally followed up to collect cameras and conduct interviews. In essence, researchers may need to assume more of the logistical responsibilities themselves instead of leaving it to participants who rightly have other priorities.

Research efforts need to be built around the fluidity of life on the street, and in this regard, research and co-design involving the homeless population are in many ways similar to working in developing regions [32]. For individuals who live day to day, two weeks can see a number of dramatic changes in location, mind set, and health. The Radley et al. study of the London homeless population addressed these challenges by limiting camera time to three days and in so doing, capitalized on the initial excitement and momentum generated as participants took up the cameras [31].

Mental illness and drug addiction pose another set of challenges when working with this community. Many of the participants in our study had spent a large portion of their adult lives in and out of homelessness following the wax and wane of gainful employment, health, and addiction. As such, several suffered memory and other mental disabilities. Depression and anxiety were common, as were minor abuses of prescription medication, like taking sedatives first thing in the morning. Using photographs to drive the interview was invaluable as a tool to jog memory, establish context, and shape the interview around personal and relevant details in their lives.

Finally, as a researcher, it is difficult to spend any amount of time with members of the homeless community and not be affected by their stories, their struggles, their sense of humor, and their humanity. The need to remain dispassionate, to establish and maintain firm boundaries, must be reaffirmed regularly [13]. The challenge here is to keep a broader perspective in the face of individual needs.

\section{CONCLUSION}

Our work is the first that we are aware of to take a systematic look at whether technologies_-including new ones that we create-might empower homeless persons in their lives. Through the interviews we held, and our subsequent analysis, we show a number of themes in how our participants per- ceive technology as well as the activities and constraints that inform how technology fits into their world. While we are not able to specifically comment on the needs of homeless families or on the unique requirements of homeless singleparents, the themes presented here penetrate a number of facets of being homeless and provide a broad base for reflecting on the complex range of needs present in that particular user community. Our findings lead us to believe that there are opportunities for productive technological interventions in the lives of homeless people. For example, the recognized utility of a cell phone provides a versatile platform for exploring different forms of technological intervention and the social impact of improving connections-both literal through being able to call friends and family for support, and symbolic as a talisman of belonging to society.

We have also begun to challenge some of the assumptions HCI makes about the relationship between people in technology. The social dynamics that are playfully exposed through urban computing ideas could be more thoughtfully considered in their relation to the less-priviledged participants of the urban environment. Appropriate technologies need to consider more than the usability or psychological appropriateness of an interaction. We need to put careful thought into the social impact technologies have for nonusers as well as users. In using technology to redefine boundaries, we have an opportunity to do so inclusively, bringing the periphery into sharper focuses, inviting in the disenfranchised and the under-served.

\section{ACKNOWLEDGMENTS}

We would like to thank Sarita Yardi for seeding the idea to investigate the homeless population and for providing invaluable support and encouragement throughout this work. We would also like to thank Beki Grinter and Paul Dourish for their insightful comments on an earlier draft of this paper.

\section{REFERENCES}

1. S. Alexander, P. Edwards, and K. Fisher. Homelessness in Eastern King County: Information Flow, Human Service Needs, and Pivotal Interventions.

2. M. Augé. Non-Places: Introduction to an Anthropology of Supermodernity. Verso Books, 1995.

3. L. J. Axelson and P. W. Dail. The Changing Character of Homelessness in the United States. Family Relations, 37(4):463-469, Oct. 1988.

4. A. Bassoli, J. Brewer, and K. Martin. In-between Theory and Practice: Dialogues in Design Research. In CHI '07: CHI '07 extended abstracts on Human factors in computing systems, pages 1691-1696, New York, NY, USA, 2007. ACM Press.

5. S. Carter and J. Mankoff. When participants do the capturing: the role of media in diary studies. In $\mathrm{CHI}$ '05: Proceedings of the SIGCHI conference on Human factors in computing systems, pages 899-908, New York, NY, USA, 2005. ACM Press.

6. E. A. Chatman. The Impoverished Life-World of Outsiders. Journal of the American Society for Information Science, 47(3):193-206, March 1996.

7. M. Chetty and R. Grinter. HCI4D: hci challenges in the global south. In CHI '07: CHI '07 extended abstracts 
on Human factors in computing systems, pages 2327-2332, New York, NY, USA, 2007. ACM Press.

8. C. D. Clark. The Autodriven Interview: A Photographic Viewfinder into Children's Experience. Visual Sociology, 14, 1999.

9. M. Clark-IbáÑez. Framing the Social World With Photo-Elicitation Interviews. American Behavioral Scientist, 47(12):1507-1527, 2004.

10. D. C. Conley. Getting It Together: Social and Institutional Obstacles to Getting off the Streets. Sociological Forum, 11(1):25-40, 1996.

11. E. R. Danseco and E. W. Holden. Are There Different Types of Homeless Families? A Typology of Homeless Families Based On Cluster Analysis. Family Relations, 47(2):159-165, April 1998.

12. C. DiSalvo and J. Vertesi. Imaging the city: exploring the practices and technologies of representing the urban environment in HCI. In CHI '07: CHI '07 extended abstracts on Human factors in computing systems, pages 2829-2832, New York, NY, USA, 2007. ACM Press.

13. J. Ensign. Ethical issues in qualitative health research with homeless youths. Journal of Advanced Nursing, 43(1):43-50, 2003.

14. M. Foth. Facilitating Social Networking in Inner-City Neighborhoods. Computer, 39(9):44-50, 2006.

15. B. Friedman. Value-sensitive design. interactions, 3(6):16-23, 1996.

16. B. Friedman, editor. Human values and the design of computer technology. Cambridge University Press, 1997.

17. W. W. Gaver, T. Dunne, and E. Pacenti. Design: Cultural probes. interactions, 6(1):21-29, 1999.

18. R. Gerena-Morales. Hawaii's Housing Boom Takes a Toll on the Homeless. The Wall Street Journal, page 1, Jan. 112007.

19. E. Goffman. The Presentation of Self in Everyday Life. Anchor Books, 1959.

20. M. S. Granovetter. The Strength of Weak Ties. The American Journal of Sociology, 78(6):1360-1380, 1973.

21. R. E. Grinter and M. Eldridge. y do tngrs luv 2 txt msg? In Proceedings of the 7th European Conference on Computer-Supported Cooperative Work (ECSCW), pages 219-238, Bonn, Germany, Sept. 16-20 2001.

22. D. Harper. Talking about pictures: a case for photo elicitation. Visual Studies, 17(1):13-26, 2002.

23. J. Hersberger. Everyday information needs and information sources of homeless parents. New Review of Information Behaviour Research, 2(Nov.):119-134, 2001.

24. J. Hersberger. Are the Economically Poor Information Poor? Does the Digital Divide affect the Homeless and Access to Information? Canadian Journal of Information \& Library Sciences, 27(3):45-63, Sept. 2002/2003.

25. J. Hersberger. A qualitative approach to examining information transfer via social networks among homeless populations. New Review of Information Behaviour Research, 4(1):95-108, 2003.
26. J. Hersberger. The Homeless and Information Need and Services. Reference and User Services Quarterly, 44(3):199-202, Spring 2005.

27. M. Muñoz, C. Vázquez, and J. J. Vázquez. A Comparison between Homeless, Domiciled and Vulnerable Populations in Madrid. Population (Enlgish Edition, 2002), 59(1):129-141, Jan.-Feb. 2004.

28. D. Norman. The Psychology of Everyday Things. Basic Books, 1988.

29. E. Paulos and E. Goodman. The familiar stranger: anxiety, comfort, and play in public places. In $\mathrm{CHI}$ '04: Proceedings of the SIGCHI conference on Human factors in computing systems, pages 223-230, New York, NY, USA, 2004. ACM Press.

30. E. Paulos and T. Jenkins. Urban probes: encountering our emerging urban atmospheres. In $\mathrm{CHI}$ '05:

Proceedings of the SIGCHI conference on Human factors in computing systems, pages 341-350, New York, NY, USA, 2005. ACM Press.

31. A. Radley, D. Hodgetts, and A. Cullen. Visualizing Homelessness: A Study in Photography and Estrangement. Journal of Community \& Applied Social Psychology, 15:273-295, 2005.

32. D. Ramachandran, M. Kam, J. Chiu, J. Canny, and J. F. Frankel. Social dynamics of early stage co-design in developing regions. In $\mathrm{CHI}$ '07: Proceedings of the SIGCHI conference on Human factors in computing systems, pages 1087-1096, New York, NY, USA, 2007. ACM Press.

33. J. Rieman. The diary study: a workplace-oriented research tool to guide laboratory efforts. In $\mathrm{CHI}$ '93: Proceedings of the INTERACT '93 and CHI '93 conference on Human factors in computing systems, pages 321-326, New York, NY, USA, 1993. ACM Press.

34. A. B. Shlay and P. H. Rossi. Social Science Research and Contemporary Studies of Homelessness. Annual Review of Sociology, 19:129-160, 1992.

35. D. A. Snow and L. Anderson. Identity Work Among the Homeless: The Verbal Construction and Avowal of Personal Identities. The American Journal of Sociology, 92(6):1336-1371, May 1987.

36. J. P. Spradley. You Owe Yourself a Drunk: An Ethnography of Urban Nomads. Little, Brown, Boston, 1970.

37. C. J. Tompsett, P. A. Toro, M. Guzicki, M. Manrique, and J. Zatakia. Homelessness in the United States: Assessing Changes in Prevalence and Public Opinion, 1993-2001. American Journal of Community Psychology, 37(1/2):47-61, 2006.

38. U. S. Department of Housing and Urban Development, Office of Community Planning and Development. Annual Homeless Assessment Report to Congress. Technical report, U. S. Department of Housing and Urban Development, Office of Community Planning and Development., Feb. 2007.

39. S. P. Wyche, P. Sengers, and R. E. Grinter. Historical Analysis: Using the Past to Design the Future. In Proceedings of UBICOMP 2006, September 17-21 2006. 